\title{
Review Article \\ Multifaceted Roles of Cysteinyl Leukotrienes in Eliciting Eosinophil Granule Protein Secretion
}

\author{
Renata Baptista-dos-Reis, Valdirene S. Muniz, and Josiane S. Neves \\ Institute of Biomedical Sciences, Federal University of Rio de Janeiro, Centro de Ciências da Saúde (CCS), \\ 373 Carlos Chagas Filho Avenue, Room F 14, 1st Floor, Ilha do Fundão, 21941-590 Rio de Janeiro, RJ, Brazil
}

Correspondence should be addressed to Josiane S. Neves; josiane.sabbadini.neves@gmail.com

Received 12 June 2014; Accepted 9 October 2014

Academic Editor: Ruxana Sadikot

Copyright (C) 2015 Renata Baptista-dos-Reis et al. This is an open access article distributed under the Creative Commons Attribution License, which permits unrestricted use, distribution, and reproduction in any medium, provided the original work is properly cited.

\begin{abstract}
Cysteinyl leukotrienes (cysLTs) are cell membrane-impermeant lipid mediators that play major roles in the pathogenesis of

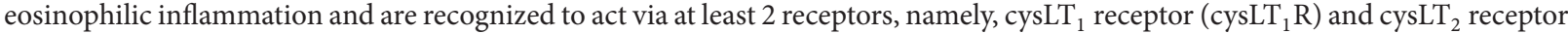
$\left(\right.$ cys $\left.\mathrm{T}_{2} \mathrm{R}\right)$. Eosinophils, which are granulocytes classically associated with host defense against parasitic helminthes and allergic conditions, are distinguished from leukocytes by their dominant population of cytoplasmic crystalloid (also termed secretory, specific, or secondary) granules that contain robust stores of diverse preformed proteins. Human eosinophils are the main source of cysLTs and are recognized to express both cysLTs receptors (cysLTRs) on their surface, at the plasma membrane. More recently, we identified the expression of cysLTRs in eosinophil granule membranes and demonstrated that cysLTs, acting via their granule membrane-expressed receptors, elicit secretion from cell-free human eosinophil granules. Herein, we review the multifaceted roles of cysLTs in eliciting eosinophil granule protein secretion. We discuss the intracrine and autocrine/paracrine secretory responses evoked by cysLTs in eosinophils and in cell-free extracellular eosinophil crystalloid granules. We also discuss the importance of this finding in eosinophil immunobiology and speculate on its potential role(s) in eosinophilic diseases.
\end{abstract}

\section{Introduction}

Cysteinyl leukotrienes (cysLTs) constitute an important class of potent proinflammatory mediators. These leukotrienes are synthesized from membrane-derived arachidonic acid via the 5-lipoxygenase (5-LO) pathway in concert with the 5-LO-activating protein (FLAP), forming $\mathrm{LTA}_{4}$, which is converted into $\mathrm{LTC}_{4}$ by the action of $\mathrm{LTC}_{4}$ synthase [1]. The production of $\mathrm{LTC}_{4}$ within cells may occur at perinuclear membranes or in cytoplasmic lipid bodies, which are cytoplasmic organelles rich in lipids. The formation of these bodies is highly regulated, and they have functions in eicosanoid production and storage of inflammatory proteins [2]. Intracellular $\mathrm{LTC}_{4}$ is actively transported extracellularly, where it is enzymatically sequentially converted to $\mathrm{LTD}_{4}$ and then to $\mathrm{LTE}_{4}$ [1]. CysLTs are cell membrane-impermeant and are recognized to mediate their actions by engaging at least two heptahelical G protein-coupled receptors (GPCRs), designated cysLT ${ }_{1}$ receptor $\left(\operatorname{cysLT}_{1} \mathrm{R}\right)$ and cysLT ${ }_{2}$ receptor $\left(\operatorname{cys}_{2} \mathrm{R}\right)$, which are expressed on the cell surface, at the plasma membrane $[1,3]$. The rank orders of the affinities of cysLTs for human cysLT ${ }_{1} \mathrm{R}$ and cysLT 2 R, based on research in transfected cells, are $\mathrm{LTD}_{4} \gg \mathrm{LTC}_{4}=\mathrm{LTE}_{4}$ and $\mathrm{LTC}_{4}=$ $\mathrm{LTD}_{4}>\mathrm{LTE}_{4}$, respectively $[4,5]$. However, various findings suggest the existence of another not yet cloned cysLT receptor (cysLTR), since numerous cysLTs' biological actions are not well explained by their affinities to the known cysLTRs [611]. For instance, experiments in animal models and human studies have revealed that $\mathrm{LTE}_{4}$, considered the weakest cysLTRs agonist, has unique characteristics that cannot be explained by current knowledge of cysLT $\mathrm{T}_{1} \mathrm{R}$ and cysLT $\mathrm{T}_{2} \mathrm{R}$ [9-11]. Moreover, an additional receptor sensitive to $\mathrm{LTE}_{4}$, the purinergic $\mathrm{P} 2 \mathrm{Y} 12$ receptor (P2Y12R), has been identified by in silico and in vivo methods $[12,13]$. In contrast, other studies have suggested that $\mathrm{LTE}_{4}$, as well as other cysLTs, does not activate intracellular signaling by acting through $\mathrm{P} 2 \mathrm{Y} 12 \mathrm{R}$ and that another $\mathrm{LTE}_{4}$-specific receptor has yet to be identified [14]. In fact, homo- and heterodimerization of 
cysLTRs and purinergic receptors have been widely suggested $[15,16]$. Whether the 3 candidate cysLTRs function or interact as homo- or heterodimers is not known. More studies are still needed to better clarify this point.

Human eosinophils are major sources of cysLTs and express both cysLT ${ }_{1} \mathrm{R}$ and cysLT $_{2} \mathrm{R}$ on their plasma membranes $[1,17]$. CysLTs and their receptors have critical roles in allergic diseases and represent important therapeutic targets for the control of asthma and other pathophysiological conditions $[15,18]$. Within eosinophils, synthesis of $\mathrm{LTC}_{4}$ (but not extracellularly formed $\mathrm{LTD}_{4}$ or $\mathrm{LTE}_{4}$ ) occurs at perinuclear membranes and in cytoplasmic lipid bodies [17]. Mature eosinophils contain a single population of secondary (or specific or crystalloid) granules that are ultrastructurally characterized as membrane-bound organelles containing a crystalloid core surrounded by a matrix. Based on diverse electron microscopy and subcellular fractionation studies, it is now recognized that human eosinophils synthesize and store cationic proteins, such as eosinophil cationic protein (ECP), eosinophil-derived neurotoxin (EDN), eosinophil peroxidase (EPO), eosinophil granule major basic protein 1 (MBP-1), enzymes, growth factors, chemokines (such as RANTES and eotaxin), and over 36 cytokines (including Th1 and Th2 cytokines) that are selectively secreted in response to a range of stimuli and agonists [19-26]. Mechanisms for differentially mobilizing these granule-stored proteins for their extracellular release may enable eosinophils to selectively and rapidly influence various immune, inflammatory, and other responses. The secretion of granule contents from intact eosinophils primarily occurs by a mechanism termed piecemeal degranulation (PMD). This is a process whereby granule contents are selectively mobilized into spherical and tubular vesicles that need to disengage from the granules, transit through the cytoplasm, and fuse with the plasma membrane to release their specific granule-derived protein cargo at the cell surface $[21,23,27]$. Another mechanism of human eosinophil "degranulation" is associated with cytolysis. Following lysis of an eosinophil, with loss of its plasma membrane integrity, intact, cell-free, membrane-bound granules are released and deposited extracellularly. Although PMD is considered to be the predominant mechanism underlying eosinophil degranulation and secretion, cytolysis has been recognized as a common mechanism for cell-free eosinophil granule release and deposition in tissues in eosinophilic diseases [28-31]. Compound exocytosis, whereby the entire granule contents are released extracellularly following fusion of the granules with the plasma membrane, occurs when eosinophils interact with large targets, such as helminthic parasites. However, this process is not usually observed in vivo.

Given that the selective release of cytokines can provide a mean for eosinophils to rapidly influence adjacent cells in normal or inflamed tissues, investigation of the mechanisms involved in the selective mobilization and vesicle-mediated secretion of specific cytokines, including IL-4 and other preformed cytokines, is extremely relevant. Several studies have provided new insights into the signal transduction processes that contribute to the selective mobilization and release of specific eosinophil granule-derived cytokines and chemokines [22, 32-36]. Several of these studies have identified the intracellular expression of cysLTRs and cysLT production as important inflammatory mediators eliciting the secretion of specific cytokines from eosinophils and from cell-free extracellular eosinophil granules [32-34, 36]. It appears increasingly likely that eicosanoids synthesized within cells, including eosinophils, may have other important intracrine roles in regulating cell functions, in addition to their more recognized autocrine/paracrine activities in inflammation.

\section{CysLTs Are Intracrine Signals Regulating Eosinophils' IL-4 Secretion by Piecemeal Degranulation}

In eosinophils, it is noteworthy that in addition to their recognized activities as autocrine/paracrine mediators, eicosanoids such as cysLTs are now also recognized to display intracrine effects. The cysLTs, $\mathrm{LTC}_{4}$, and their extracellular derivatives, $\mathrm{LTD}_{4}$ and $\mathrm{LTE}_{4}$, are recognized as paracrine mediators pertinent to asthma and allergic diseases based on their receptormediated capabilities to elicit bronchoconstriction, mucous hypersecretion, bronchial hyperresponsiveness, increased microvascular permeability, and additional eosinophil infiltration $[1,15,18,37]$. Eosinophils are major sources of cysLTs [17] and are the principal LTC $_{4}$ synthase-expressing cells in bronchial mucosa biopsy specimens from asthmatic subjects, as well as being recognized to express both cysLTRs [1, 17]. Thus, cysLTs are also important autocrine regulators of eosinophil function. Indeed, a series of reports showed that cysLTs have the ability to affect various eosinophil responses [35, 38-41]. For instance, in eosinophils derived from human cord blood progenitors in vitro, it was shown that $\mathrm{LTC}_{4}$, $\mathrm{LTD}_{4}$, and $\mathrm{LTE}_{4}$ induced dose- and time-dependent, vesicular transport-mediated release of preformed IL-4 [38]. Although controversy exists [39], cysLTs also appear to be able to induce the in vitro survival of human eosinophils by activation of cysLT $_{1} \mathrm{R}$ [40, 41]. Additionally it was demonstrated that enhanced plasma membrane expression of activation-related CD69 on human eosinophils induced by platelet-activating factor (PAF) and IL-5 is dependent on endogenous eosinophil-derived 5-LO metabolites [35]. Consequently, much interest in understanding the regulation of eicosanoid formation in eosinophils has focused on the mechanisms that regulate eosinophil cysLT formation and release. Interestingly, it was noted that depending on the stimulus, the localized synthesis of $\mathrm{LTC}_{4}$ may occur at distinct intracellular sites within eosinophils (at the perinuclear membrane and/or in lipid bodies) and may control the role of this mediator as either an intracrine signal-transducing mediator that regulates PMD and cytokine secretion or an autocrine/paracrine element in eosinophilic inflammation [2, 32, 36]. In 2002, Bandeira-Melo and colleagues [32] evaluated whether cysLTs function as intracrine mediators involved in the stimulated release of IL- 4 from eosinophils. The authors demonstrated that although eotaxin and RANTES each act via CCR3 to stimulate the secretion of both IL-4 and RANTES from eosinophils, only the release of IL-4 was dependent 


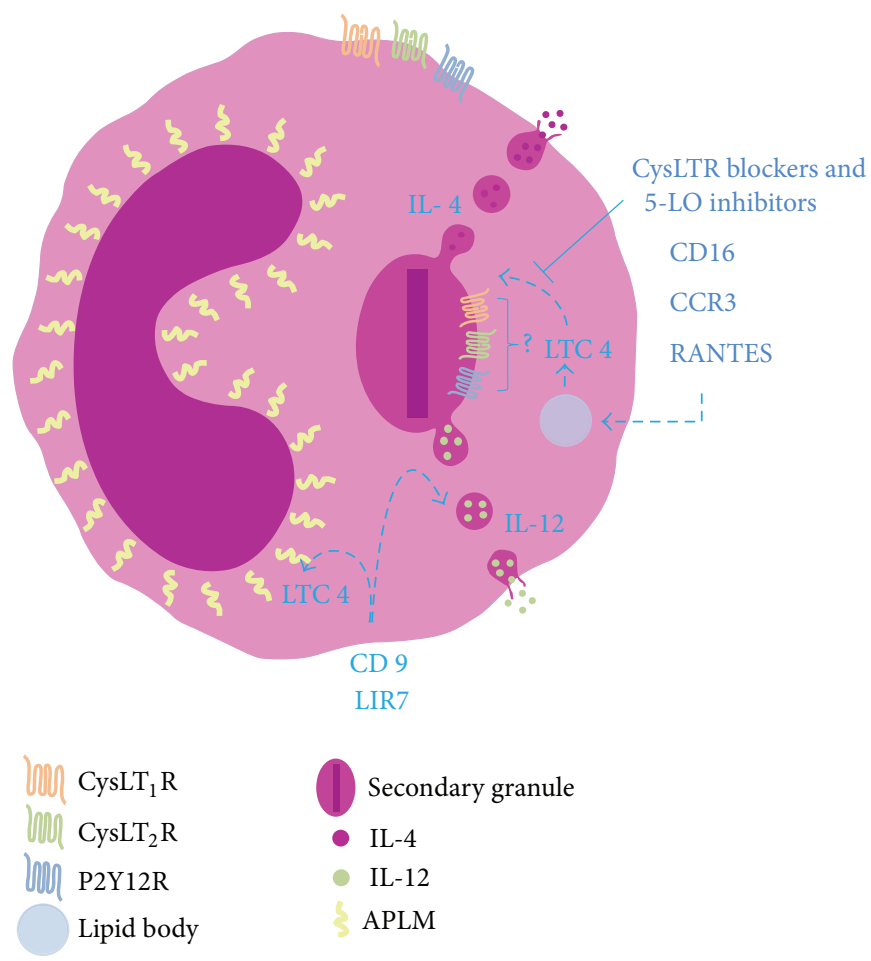

FIGURE 1: CysLTs are intracrine signals regulating eosinophils' IL-4 secretion by piecemeal degranulation.IL-4 release induced by IL-16, eotaxin, and RANTES is dependent on the intracrine action of lipid body-generated $\mathrm{LTC}_{4}$. Inhibitors of 5-lypoxigenase (5-LO) and/or cysteinyl leukotriene receptors (cysLTRs) blocked intracellular LTC 4 production and consequently IL-4 release from eosinophils. The crosslinking of LIR7- or CD9-induced perinuclear-generated $\mathrm{LTC}_{4}$, however IL-12 secretion induced by LIR7 or CD9 is independent of 5$\mathrm{LO}$ metabolites. CysLT $\mathrm{R}=$ cysLT 1 receptor; cysLT $_{2} \mathrm{R}=$ cysLT $_{2}$ receptor, $\mathrm{P} 2 \mathrm{Y} 12 \mathrm{R}=$ purinergic $\mathrm{P} 2 \mathrm{Y} 12$ receptor, and $\mathrm{APLM}=$ arachidonyl phospholipids and lipoxygenase machinery.

on the activation of 5-LO to form $\mathrm{LTC}_{4}$ within eosinophils' lipid bodies. Inhibitors of 5-LO blocked IL-16-, eotaxin-, and RANTES-induced IL-4 release, but exogenous $\mathrm{LTC}_{4}, \mathrm{LTD}_{4}$, and $\mathrm{LTE}_{4}$ did not elicit IL-4 release. Only after membrane permeabilization were cysLTs enabled to enter eosinophils and stimulate IL- 4 but not RANTES release. LTC $_{4^{-}}$and $\mathrm{LTD}_{4}$-elicited IL-4 release was pertussis toxin inhibitable, but inhibitors of the two known GPCRs, cysLT $_{1} \mathrm{R}$ and cysLT $2 \mathrm{R}$, did not block $\mathrm{LTC}_{4}$-elicited IL-4 release. $\mathrm{LTC}_{4}$ was more potent than $\mathrm{LTD}_{4}$ was and, at low concentrations, elicited IL-4 release from permeabilized eosinophils, whereas higher concentrations were inhibitory probably due to the high-dose inhibition characteristic of the GPCRs. For intact eosinophils, also as a consequence of high intracellular $\mathrm{LTC}_{4}$ levels, $\mathrm{LTC}_{4}$ export inhibitors blocked eotaxin-elicited IL-4 release. Thus, taken together, these data demonstrate that despite being well recognized as an autocrine/paracrine mediator, $\mathrm{LTC}_{4}$, via an intracellular cysLTR distinct from cysLT ${ }_{1} \mathrm{R}$ and cysLT $\mathrm{R}_{2} \mathrm{R}$, may also dynamically govern inflammatory responses as an intracrine mediator of eosinophils' PMD-mediated cytokine secretion (Figure 1).

Interestingly, in a different study, Tedla and colleagues showed that the cross-linking of leukocyte immunoglobulinlike receptor 7 (LIR7) and CD9 with immobilized antibodies induced $\mathrm{LTC}_{4}$ generation at the nuclear envelope and the release of IL-12, but not IL-4, by vesicular transport [36]. Whereas the IL-4 release induced by IL-16 and CCR3-activating chemokines is dependent on the intracrine action of lipid body-generated $\mathrm{LTC}_{4}$ [32], the IL-12 release induced by the cross-linking of LIR7 does not appear to be regulated by 5 -LO metabolites $[36,42]$. Pretreatment with two mechanistically distinct inhibitors of 5-LO (AA861 and MK886) blocked IL-16-, eotaxin-, and RANTES-induced $\mathrm{LTC}_{4}$ production and IL-4 release from eosinophils [32]. In contrast, pretreatment of eosinophils with either AA861 or MK886 did not inhibit the selective release of IL-12 induced by the cross-linking of CD9 or LIR7, indicating that 5LO does not participate in CD9- or LIR7-driven selective IL-12 release $[36,42]$. Moreover, stimulation of permeabilized eosinophils with $\mathrm{LTC}_{4}$ did not elicit IL-12 release [36]. Overall, intracellular $\mathrm{LTC}_{4}$ formed in lipid bodies appears to function as an intracrine, and not an extracellular autocrine/paracrine, mediator to regulate the differential secretion of IL-4 induced by IL-16, eotaxin, or RANTES [32]. Meanwhile, the intracellular 5-LO-derived $\mathrm{LTC}_{4}$ formed at the perinuclear membrane appears not to control the selective IL-12 release induced by the cross-linking of CD9 or LIR7 and may function as an autocrine/paracrine mediator of inflammation [36]. These studies suggest that the capacity of eosinophils to synthesize $\mathrm{LTC}_{4}$ in lipid bodies may relate 
less to paracrine mediator formation and more to intracrine signal-transducing activities pertinent to more local transcriptional or other cellular functions [43] (Figure 1).

Possible intracrine roles for $\mathrm{LTC}_{4}$ have also been described in other cell types, including vascular and mast cells; however, how $\mathrm{LTC}_{4}$ acts intracellularly remains to be defined [44-46]. Although eosinophils express the two known cysLTRs, cysLT ${ }_{1} \mathrm{R}$ and cysLT $_{2} \mathrm{R}[17,42]$, little is known about the intracellular distribution of these receptors in eosinophils. In addition to its conventional plasma membrane expression, cysLT ${ }_{1} \mathrm{R}$ has been immunolocalized to nuclei in colorectal adenocarcinoma cells [47], in a human mast cell line [48] and in vascular smooth muscle cells [46]. The functions of nuclear cysLT $\mathrm{R}_{1} \mathrm{R}$ are poorly understood. For instance, in one interesting study, Nielsen and colleagues demonstrated that isolated intestinal cell nuclei express cysLT 1 R and respond to $\mathrm{LTD}_{4}$, triggering ERK1/2 signaling [47]. However, whether these nuclear-localized receptors are involved in the cell cycle (for survival or proliferation) is still unknown. In a different study, Eaton and colleagues showed that LPS upregulated the perinuclear expression of $\operatorname{cysLT}_{1} \mathrm{R}$ in vascular smooth muscle cells and that LTC $_{4}$ stimulation predominantly enhanced nuclear calcium increase and gene transcription [46]. Whether or how exogenous $\mathrm{LTC}_{4}$ reaches these intracellular cysLT ${ }_{1}$ Rs is still not defined. Recently, we defined the intracellular expression of cysLT-sensitive receptors in crystalloid granule membranes [34]. These findings might help in identifying novel mechanisms whereby cysLTs can serve as intracrine mediators.

\section{Extracellular Eosinophil Granules Express Ligand-Binding Domains for CysLTRs on Their Membranes and Secrete ECP in Response to CysLTs}

Intracrine roles for cysLTs are described in the literature, but the mechanisms involved that can explain cysLTs' intracellular actions remain unknown $[32,44,45]$. A description of intracellular cysLTRs expression in human eosinophils was recently provided by our group [34]. In 2010, we reported, for the first time, that the receptors for cysLTs, cysLT ${ }_{1} \mathrm{R}$ and $\operatorname{cysLT}_{2} \mathrm{R}$, and the purinergic $\mathrm{P} 2 \mathrm{Y} 12 \mathrm{R}$ are expressed on eosinophil granule membranes [34]. We showed that eosinophil granules express amino-terminal, ligand-binding domains for cysLT ${ }_{1} \mathrm{R}$ and cysLT $_{2} \mathrm{R}$ and the P2Y12R on their membranes. We previously observed that certain cytokine and chemokine receptors are richly present on eosinophil granules $[22,33,49]$. These granules, upon extrusion from eosinophils, responded to a stimulating cytokine, interferon$\gamma$, and a chemokine, eotaxin-1 (CCL11), via cognate granule membrane-expressed receptors to activate intragranular signaling pathways that elicit granule protein secretion $[33,50]$. Stimulating cell-free eosinophil granules with the agonists $\mathrm{LTC}_{4}, \mathrm{LTD}_{4}$, and $\mathrm{LTE}_{4}$ elicited the secretion of ECP, but not eosinophil-derived cytokines or chemokines, from the granules (as detected by cytokine multiplex assays). Montelukast, a recognized inhibitor that principally inhibits
cysLT $_{1} \mathrm{R}$, as well as the P2Y12R antagonist MRS 2395, inhibited eosinophil granule ECP secretion after $\mathrm{LTC}_{4} / \mathrm{LTD}_{4} / \mathrm{LTE}_{4}$ stimulation of cell-free eosinophil granules [34] (Figure 2). The capacity of a cysLT $\mathrm{R}_{1}$ inhibitor or a P2Y12R antagonist, such as montelukast and MRS 2395, respectively, to similarly inhibit the secretion elicited by ligands (e.g., $\mathrm{LTE}_{4}$ ) not active for cysLT $R$ or not classically selective for the receptor (e.g., P2Y12R), suggests functional heterodimerization of cysLT $_{1} \mathrm{R}$ and other receptors (e.g., functional heterodimerization between cysLT ${ }_{1} \mathrm{R}, \operatorname{cysLT}_{2} \mathrm{R}$, and $\mathrm{P} 2 \mathrm{Y} 12 \mathrm{R}$ ) expressed on eosinophil granule membranes; whether this is the case remains to be ascertained. In addition, montelukast's potential off-target effects could not be discounted. Notably, the dose response to the three cysLTs varied. LTC $_{4}$ and $\mathrm{LTE}_{4}$ elicited ECP secretion only at lower (subnanomolar) concentrations, which was fully consistent with the high-dose inhibition characteristic of the GPCRs. Intriguingly, $\mathrm{LTD}_{4}$ elicited ECP secretion at low and high, but not intermediate, concentrations. This dose response suggests the engagement of two receptors sensitive to $\mathrm{LTD}_{4}$, with the first responding to low $\mathrm{LTD}_{4}$ levels and then exhibiting higher dose inhibition and the second receptor putatively mediating secretion at higher concentrations of $\mathrm{LTD}_{4}$. As previously mentioned, oligomerization of leukotriene and purinergic receptors has been widely suggested $[15,16]$. However, whether dimerization of receptors is involved in this response remains to be elucidated. These findings highlight the capacity of cysLTRs to stimulate cell-free granule secretory responses. Furthermore, for granules serving as intracellular organelles these data identify novel mechanisms whereby $\mathrm{LTC}_{4}$ and extracellularly generated $\mathrm{LTD}_{4}$ and $\mathrm{LTE}_{4}$ (if these mediators could be, by any chance, internalized by the cell) may serve as intracrine mediators of eosinophil granule-derived secretion. However, there is no evidence that the cysLT 1 R, cysLT 2 , or P2Y12R expressed on granule membranes is involved in the intracrine actions of cysLTs described previously [32]. This phenomenon is not likely, considering that LTC $_{4}$ - and $\mathrm{LTD}_{4}$-elicited IL-4 release in permeabilized eosinophils is not blocked by inhibitors of cysLT ${ }_{1} \mathrm{R}$ and cysLT $_{2} \mathrm{R}$ [32].

All of these findings are remarkable because they provide additional information about the capacity of eosinophils to contribute to modulating host and inflammatory responses after eosinophil cytolysis. Cytolytic release of intact eosinophil granules yields extracellular organelles fully capable of ligand-elicited active secretory responses, amplifying the differential secretory properties of eosinophils and likely contributing to the persistence and exacerbation of the inflammatory response.

\section{Implications for Eosinophilic Diseases and Eosinophil Immunobiology: Questions for the Future}

Intact membrane-bound eosinophil granules have long been recognized to be present extracellularly in tissues and secretions in many human eosinophil-enriched disorders (for review see [49]). The capacity of cell-free human eosinophil granules to act via receptor-mediated responses to cysLTs and 


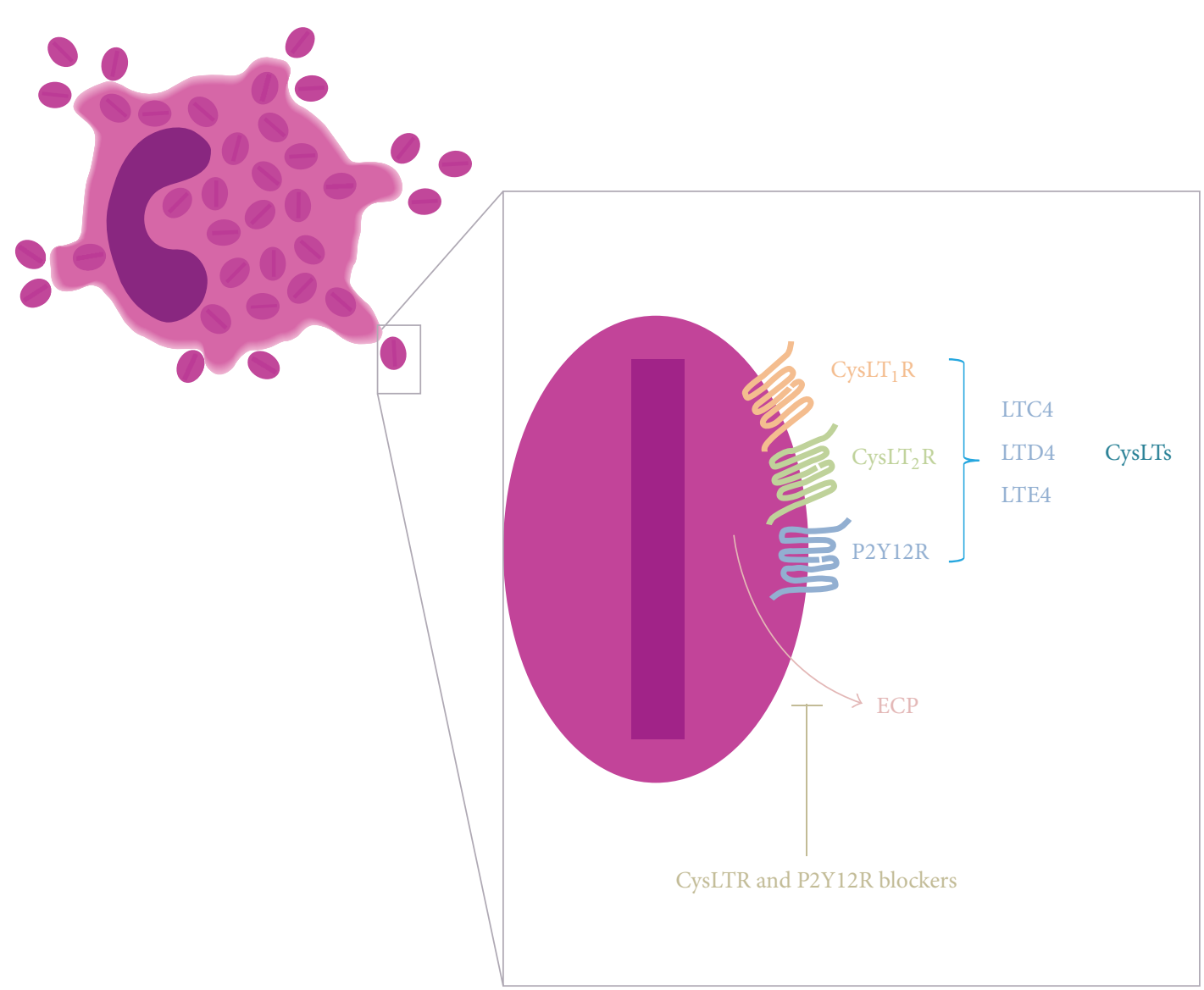

FIGURE 2: Stimulating cell-free eosinophil granules with the agonists $\mathrm{LTC}_{4}, \mathrm{LTD}_{4}$, and $\mathrm{LTE}_{4}$ elicited the secretion of eosinophil cationic protein (ECP) but not eosinophil-derived cytokines or chemokines from the granules. Cysteinyl leukotriene receptor (cysLTR) or P2Y12 receptor (P2Y12R) blockers inhibited ECP secretion after $\mathrm{LTC}_{4} / \mathrm{LTD}_{4} / \mathrm{LTE}_{4}$ stimulation of cell-free eosinophil granules.

to secrete granule-derived cationic proteins has indicated that cell-free eosinophil granules may be functionally significant in response to these lipid mediators [34], likely contributing to perpetuation of the inflammatory process in an affected organ. As intracrine mediators, the capacity of eicosanoids, such as $\mathrm{LTC}_{4}$, to be synthesized at 2 discrete sites, perinuclear membranes and lipid bodies, in eosinophils raises questions about the roles of these pools of lipids in the functioning of eosinophils in inflammation. As noted above, cysLTs are wellrecognized autocrine/paracrine mediators that are pertinent to eosinophils, asthma, and allergic inflammation; however, how these eicosanoids transit from their intracellular sites of synthesis for their extracellular release, which is requisite for their autocrine/paracrine functions, remains uncertain. This uncertainty is especially true for $\mathrm{LTC}_{4}$ formed at perinuclear membranes that are not proximate to the cell surface. Furthermore, the logic of using phospholipids resident in perinuclear membranes as a source of substrate for forming secreted eicosanoid mediators remains unclear. Therapeutic agents in current use that inhibit $5-\mathrm{LO}$ or cysLT $\mathrm{R}_{1} \mathrm{R}$ may have activities broader than simply blocking the paracrinemediator activities of cysLTs. Furthermore, with greater understanding of the intracellular sites of cysLT synthesis and cysLTR expression and of the functional consequences of such cysLTR-mediated cellular regulation for both intracellular and cell-free granules, newer therapeutic agents may be targeted to regulate specific activities of cysLTs pertinent to asthma and other allergic diseases.

Notably, studies demonstrating that isolated human eosinophil granules could exert extracellular functions as secretion-competent organelles after stimulation with ligands, including chemokines and cysLTs [33, 34], provide highly relevant observations in terms of eosinophil cell biology. Considering functional roles for these intracellular granule membrane-expressed receptors, with their ligand-binding domains displayed on the outer granule membranes, these findings not only support extracellular granule function but also suggest that the granule-expressed receptors potentially serve as intracrine mediators of eosinophil-derived granule secretion. For receptors such as the lipid-mediator receptors (cysLT ${ }_{1} \mathrm{R}$, cysLT $_{2} \mathrm{R}$, and $\mathrm{P} 2 \mathrm{Y} 12 \mathrm{R}$ ), which are activated by hydrophobic ligands that can be synthesized at the nuclear membrane or in lipid bodies, it is possible to predict roles in intracellular compartments, where they would be accessible to their ligands. For chemokine/cytokine receptors, it is also feasible that the ligands themselves are active intracellularly after their biosynthesis and/or based on specific cell uptake and internalization mechanisms. 
Current investigations are only beginning to explore the functional biology and responses of eosinophil granules. Most notably, how specific granule-derived proteins are selectively mobilized for secretion from either isolated eosinophil granules or intracellular granules by PMD within intact eosinophils is yet to be ascertained. The molecular mechanisms that regulate eosinophil granule protein mobilization and secretion continue to be intriguing and requiring further delineation.

\section{Conflict of Interests}

The authors declare that there is no conflict of interests regarding the publication of this paper.

\section{Acknowledgments}

CNPq/Brazil (to Valdirene S. Muniz, Renata Baptista-dosReis, and Josiane S. Neves) and FAPERJ/Brazil (to Valdirene S. Muniz, Renata Baptista-dos-Reis, and Josiane S. Neves) supported this work.

\section{References}

[1] M. Peters-Golden and W. R. Henderson Jr., "Leukotrienes," The New England Journal of Medicine, vol. 357, no. 18, pp. 1841-1854, 2007.

[2] P. T. Bozza, I. Bakker-Abreu, R. A. Navarro-Xavier, and C. Bandeira-Melo, "Lipid body function in eicosanoid synthesis: an update," Prostaglandins Leukotrienes and Essential Fatty Acids, vol. 85, no. 5, pp. 205-213, 2011.

[3] G. E. Rovati and V. Capra, "Cysteinyl-leukotriene receptors and cellular signals," The ScientificWorld Journal, vol. 7, pp. 13751392, 2007.

[4] C. E. Heise, B. F. O’Dowd, D. J. Figueroa et al., "Characterization of the human cysteinyl leukotriene 2 receptor," The Journal of Biological Chemistry, vol. 275, no. 39, pp. 30531-30536, 2000.

[5] K. R. Lynch, G. P. O’Neill, Q. Liu et al., "Characterization of the human cysteinyl leukotriene CysLT1 receptor," Nature, vol. 399, no. 6738, pp. 789-793, 1999.

[6] R. A. Panettieri Jr., E. M. L. Tan, V. Ciocca, M. A. Luttmann, T. B. Leonard, and D. W. P. Hey, "Effects of LTD4 on human airway smooth muscle cell proliferation, matrix expression, and contraction in vitro: differential sensitivity to cysteinyl leukotriene receptor antagonists," The American Journal of Respiratory Cell and Molecular Biology, vol. 19, no. 3, pp. 453461, 1998.

[7] E. A. Mellor, K. F. Austen, and J. A. Boyce, "Cysteinyl leukotrienes and uridine diphosphate induce cytokine generation by human mast cells through an interleukin 4-regulated pathway that is inhibited by leukotriene receptor antagonists," The Journal of Experimental Medicine, vol. 195, no. 5, pp. 583592, 2002.

[8] S. Ravasi, V. Capra, M. Mezzetti, S. Nicosia, and G. E. Rovati, "A kinetic binding study to evaluate the pharmacological profile of a specific leukotriene $\mathrm{C} 4$ binding site not coupled to contraction in human lung parenchyma," Molecular Pharmacology, vol. 57, no. 6, pp. 1182-1189, 2000.
[9] T. H. Lee, G. Woszczek, and S. P. Farooque, "Leukotriene $\mathrm{E}_{4}$ : perspective on the forgotten mediator," Journal of Allergy and Clinical Immunology, vol. 124, no. 3, pp. 417-421, 2009.

[10] K. F. Austen, A. Maekawa, Y. Kanaoka, and J. A. Boyce, "The leukotriene E4 puzzle: finding the missing pieces and revealing the pathobiologic implications," Journal of Allergy and Clinical Immunology, vol. 124, no. 3, pp. 406-414, 2009.

[11] G. M. Gauvreau, K. N. Parameswaran, R. M. Watson, and P. M. O’Byrne, "Inhaled leukotriene E4, but not leukotriene D4, increased airway inflammatory cells in subjects with atopic asthma," The American Journal of Respiratory and Critical Care Medicine, vol. 164, no. 8, part 1, pp. 1495-1500, 2001.

[12] Y. Nonaka, T. Hiramoto, and N. Fujita, "Identification of endogenous surrogate ligands for human P2Y12 receptors by in silico and in vitro methods," Biochemical and Biophysical Research Communications, vol. 337, no. 1, pp. 281-288, 2005.

[13] S. Paruchuri, H. Tashimo, C. Feng et al., "Leukotriene E4induced pulmonary inflammation is mediated by the P2Y12 receptor," Journal of Experimental Medicine, vol. 206, no. 11, pp. 2543-2555, 2009.

[14] H. R. Foster, E. Fuerst, T. H. Lee, D. J. Cousins, and G. Woszczek, "Characterisation of P2Y(12) receptor responsiveness to cysteinyl leukotrienes," PLoS ONE, vol. 8, no. 3, Article ID e58305, 2013.

[15] V. Capra, M. D. Thompson, A. Sala, D. E. Cole, G. Folco, and G. E. Rovati, "Cysteinyl-leukotrienes and their receptors in asthma and other inflammatory diseases: critical update and emerging trends," Medicinal Research Reviews, vol. 27, no. 4, pp. 469-527, 2007.

[16] G. Milligan, "G protein-coupled receptor hetero-dimerization: contribution to pharmacology and function," British Journal of Pharmacology, vol. 158, no. 1, pp. 5-14, 2009.

[17] C. Bandeira-Melo and P. F. Weller, "Eosinophils and cysteinyl leukotrienes," Prostaglandins Leukotrienes and Essential Fatty Acids, vol. 69, no. 2-3, pp. 135-143, 2003.

[18] Y. Kanaoka and J. A. Boyce, "Cysteinyl leukotrienes and their receptors: cellular distribution and function in immune and inflammatory responses," The Journal of Immunology, vol. 173, no. 3, pp. 1503-1510, 2004.

[19] C. Blanchard and M. E. Rothenberg, "Biology of the eosinophil," Advances in Immunology, vol. 101, pp. 81-121, 2009.

[20] L. A. Spencer, C. T. Szela, S. A. C. Perez et al., "Human eosinophils constitutively express multiple th1, th2, and immunoregulatory cytokines that are secreted rapidly and differentially," Journal of Leukocyte Biology, vol. 85, no. 1, pp. 117-123, 2009.

[21] R. Moqbel and J. J. Coughlin, "Differential secretion of cytokines," Science's STKE, vol. 2006, no. 338, article pe26, 2006.

[22] L. A. Spencer, R. C. N. Melo, S. A. C. Perez, S. P. Bafford, A. M. Dvorak, and P. F. Weller, "Cytokine receptor-mediated trafficking of preformed IL-4 in eosinophils identifies an innate immune mechanism of cytokine secretion," Proceedings of the National Academy of Sciences of the United States of America, vol. 103, no. 9, pp. 3333-3338, 2006.

[23] R. C. Melo, L. A. Spencer, A. M. Dvorak, and P. F. Weller, "Mechanisms of eosinophil secretion: large vesiculotubular carriers mediate transport and release of granule-derived cytokines and other proteins," Journal of Leukocyte Biology, vol. 83, no. 2, pp. 229-236, 2008. 
[24] R. C. Melo, L. A. Spencer, S. A. Perez, I. Ghiran, A. M. Dvorak, and P. F. Weller, "Human eosinophils secrete preformed, granule-stored interleukin-4 through distinct vesicular compartments," Traffic, vol. 6, no. 11, pp. 1047-1057, 2005.

[25] R. C. N. Melo, L. A. Spencer, S. A. C. Perez et al., "Vesiclemediated secretion of human eosinophil granule-derived major basic protein," Laboratory Investigation, vol. 89, no. 7, pp. 769781, 2009.

[26] V. S. Muniz, P. F. Weller, and J. S. Neves, "Eosinophil crystalloid granules: structure, function, and beyond," Journal of Leukocyte Biology, vol. 92, no. 2, pp. 281-288, 2012.

[27] R. C. N. Melo and P. F. Weller, "Piecemeal degranulation in human eosinophils: a distinct secretion mechanism underlying inflammatory responses," Histology and Histopathology, vol. 25, no. 10, pp. 1341-1354, 2010.

[28] M. Karawajczyk, L. Seveus, R. Garcia et al., "Piecemeal degranulation of peripheral blood eosinophils: a study of allergic subjects during and out of the pollen season," American Journal of Respiratory Cell and Molecular Biology, vol. 23, no. 4, pp. 521529, 2000.

[29] A. M. Dvorak and S. Kissell, "Granule changes of human skin mast cells characteristic of piecemeal degranulation and associated with recovery during wound healing in situ," Journal of Leukocyte Biology, vol. 49, no. 2, pp. 197-210, 1991.

[30] A. M. Dvorak, R. S. McLeod, A. Onderdonk et al., "Ultrastructural evidence for piecemeal and anaphylactic degranulation of human gut mucosal mast cells in vivo," International Archives of Allergy and Immunology, vol. 99, no. 1, pp. 74-83, 1992.

[31] J. S. Erjefält, L. Greiff, M. Andersson, E. Ädelroth, and C. G. A. Persson, "Degranulation patterns of eosinophil granulocytes as determinants of eosinophil driven disease," Thorax, vol. 56, no. 5, pp. 341-344, 2001.

[32] C. Bandeira-Melo, L. J. Woods, M. Phoofolo, and P. F. Weller, "Intracrine cysteinyl leukotriene receptor-mediated signaling of eosinophil vesicular transport-mediated interleukin-4 secretion," Journal of Experimental Medicine, vol. 196, no. 6, pp. 841850, 2002.

[33] J. S. Neves, S. A. C. Perez, L. A. Spencer et al., "Eosinophil granules function extracellularly as receptor-mediated secretory organelles," Proceedings of the National Academy of Sciences of the United States of America, vol. 105, no. 47, pp. 18478-18483, 2008.

[34] J. S. Neves, A. L. Radke, and P. F. Weller, "Cysteinyl leukotrienes acting via granule membrane-expressed receptors elicit secretion from within cell-free human eosinophil granules," Journal of Allergy and Clinical Immunology, vol. 125, no. 2, pp. 477-482, 2010.

[35] T. Urasaki, J. Takasaki, T. Nagasawa, and H. Ninomiya, "Pivotal role of 5-lipoxygenase in the activation of human eosinophils: platelet-activating factor and interleukin-5 induce CD69 on eosinophils through the 5-lipoxygenase pathway," Journal of Leukocyte Biology, vol. 69, no. 1, pp. 105-112, 2001.

[36] N. Tedla, C. Bandeira-Melo, P. Tassinari et al., "Activation of human eosinophils through leukocyte immunoglobulin-like receptor 7," Proceedings of the National Academy of Sciences of the United States of America, vol. 100, no. 3, pp. 1174-1179, 2003.

[37] C. Bandeira-Melo, P. T. Bozza, and P. F. Weller, "The cellular biology of eosinophil eicosanoid formation and function," Journal of Allergy and Clinical Immunology, vol. 109, no. 3, pp. 393-400, 2002.
[38] C. Bandeira-Melo, J. C. Hall, J. F. Penrose, and P. F. Weller, "Cysteinyl leukotrienes induce IL-4 release from cord bloodderived human eosinophils," Journal of Allergy and Clinical Immunology, vol. 109, no. 6, pp. 975-979, 2002.

[39] J. Murray, C. Ward, J. T. O'Flaherty et al., "Role of leukotrienes in the regulation of human granulocyte behaviour: dissociation between agonist-induced activation and retardation of apoptosis," The British Journal of Pharmacology, vol. 139, no. 2, pp. 388398, 2003.

[40] K. Becler, L. Håkansson, and S. Rak, "Treatment of asthmatic patients with a cysteinyl leukotriene receptor-1 antagonist montelukast (Singulair), decreases the eosinophil survivalenhancing activity produced by peripheral blood mononuclear leukocytes in vitro," Allergy, vol. 57, no. 11, pp. 1021-1028, 2002.

[41] E. Lee, T. Robertson, J. Smith, and S. Kilfeather, "Leukotriene receptor antagonists and synthesis inhibitors reverse survival in eosinophils of asthmatic individuals," American Journal of Respiratory and Critical Care Medicine, vol. 161, no. 6, pp. 18811886, 2000.

[42] C. Bandeira-Melo and P. F. Weller, "Mechanisms of eosinophil cytokine release," Memorias do Instituto Oswaldo Cruz, vol. 100, supplement 1, pp. 73-81, 2005.

[43] M. Peters-Golden and T. G. Brock, "Intracellular compartmentalization of leukotriene biosynthesis," The American Journal of Respiratory and Critical Care Medicine, vol. 161, no. 2, part 2, pp. S36-S40, 2000.

[44] Y. Jiang, Y. Kanaoka, C. Feng, K. Nocka, S. Rao, and J. A. Boyce, "Cutting edge: interleukin 4-dependent mast cell proliferation requires autocrine/intracrine cysteinyl leukotrieneinduced signaling," Journal of Immunology, vol. 177, no. 5, pp. 2755-2759, 2006.

[45] J. C. González-Cobos, X. Zhang, W. Zhang et al., "Storeindependent Orail/3 channels activated by intracrine leukotriene $\mathrm{C}_{4}$ : role in neointimal hyperplasia," Circulation Research, vol. 112, no. 7, pp. 1013-1025, 2013.

[46] A. Eaton, E. Nagy, M. Pacault, J. Fauconnier, and M. Bäck, "Cysteinyl leukotriene signaling through perinuclear CysLT receptors on vascular smooth muscle cells transduces nuclear calcium signaling and alterations of gene expression," Journal of Molecular Medicine, vol. 90, no. 10, pp. 1223-1231, 2012.

[47] C. K. Nielsen, J. I. A. Campbell, J. F. Öhd et al., "A novel localization of the G-protein-coupled CysLT1 receptor in the nucleus of colorectal adenocarcinoma cells," Cancer Research, vol. 65, no. 3, pp. 732-742, 2005.

[48] Y. Jiang, L. A. Borrelli, Y. Kanaoka, B. J. Bacskai, and J. A. Boyce, "CysLT2 receptors interact with CysLT1 receptors and downmodulate cysteinyl leukotriene-dependent mitogenic responses of mast cells," Blood, vol. 110, no. 9, pp. 3263-3270, 2007.

[49] J. S. Neves and P. F. Weller, "Functional extracellular eosinophil granules: novel implications in eosinophil immunobiology," Current Opinion in Immunology, vol. 21, no. 6, pp. 694-699, 2009.

[50] J. S. Neves, S. A. C. Perez, L. A. Spencer, R. C. N. Melo, and P. F. Weller, "Subcellular fractionation of human eosinophils: isolation of functional specific granules on isoosmotic density gradients," Journal of Immunological Methods, vol. 344, no. 1, pp. 64-72, 2009. 

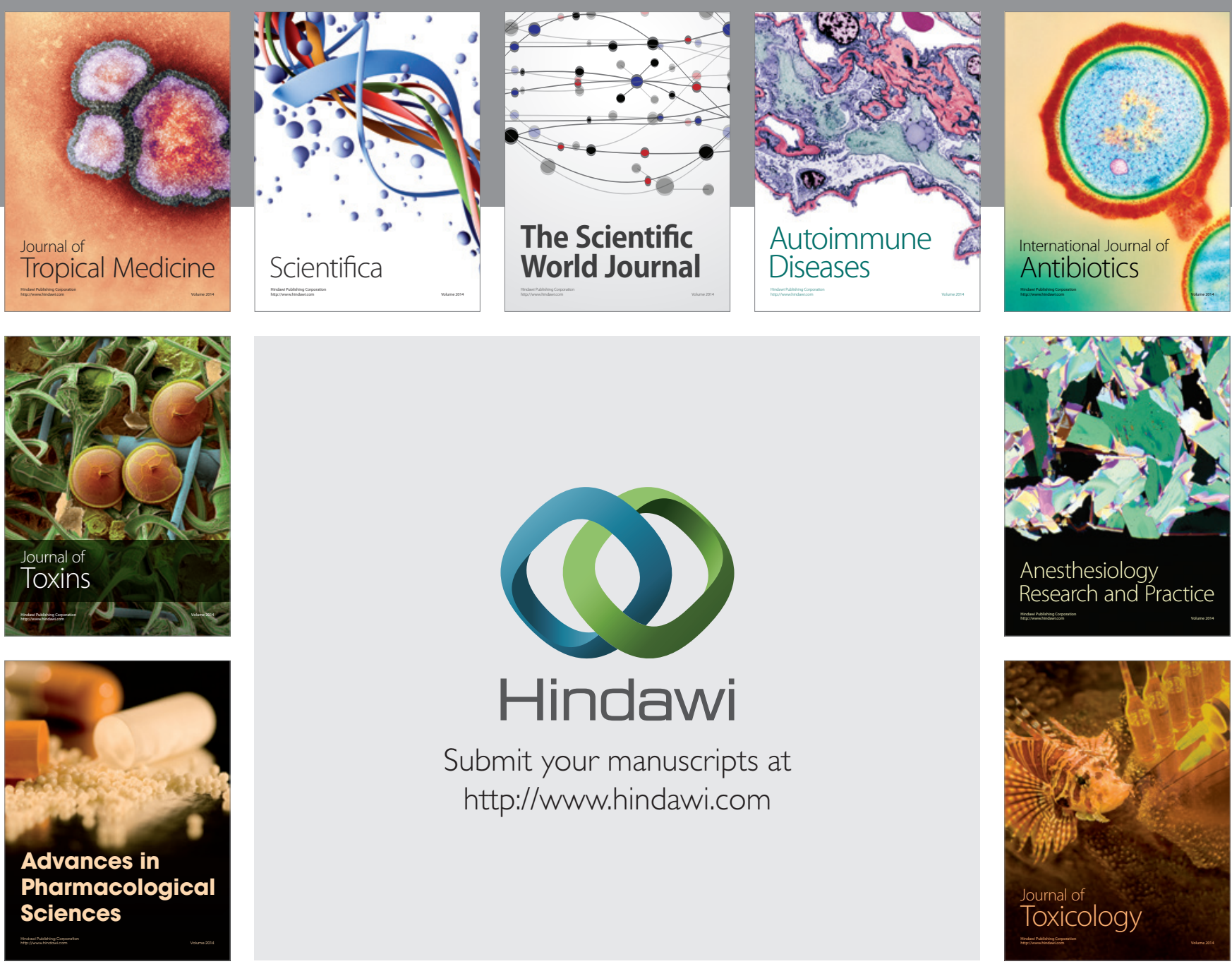

\section{Hindawi}

Submit your manuscripts at

http://www.hindawi.com
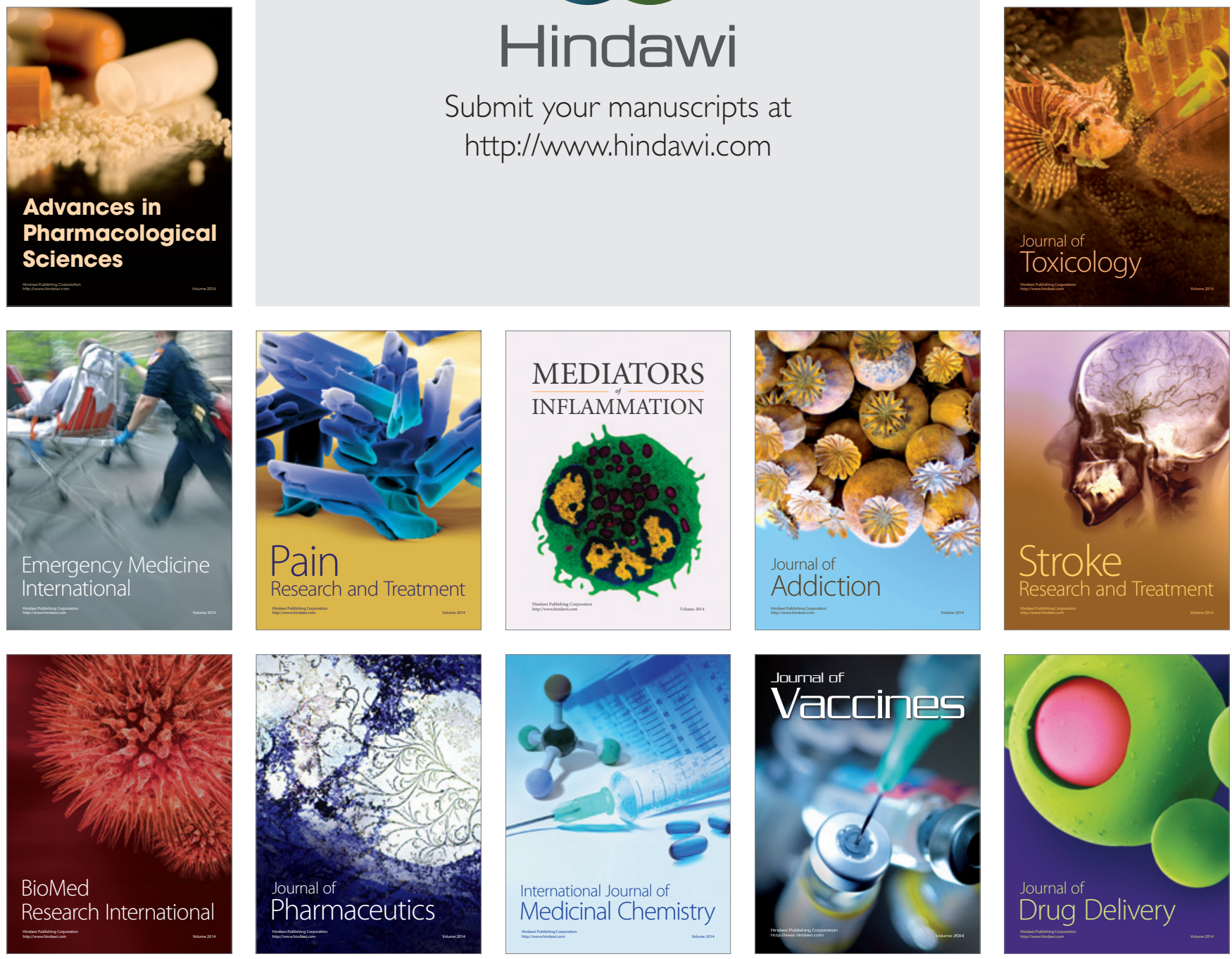